Background: Attitudes and beliefs about pain determine the interpersonal interaction in evaluation and treatment of a chronic painful condition like fibromyalgia in a multidisciplinary healthcare system. Two distinct dimensions for pain attitudes and beliefs were identified as Biomedical and Behavioral. The former utilized a pathoanatomical model whereas the latter incorporated the psychosocial factors into clinical presentations.

Objectives: The study aimed to evaluate the pain attitudes and beliefs amongst rhematologists, physical therapists and fibromyalgia patients and to compare the biomedical and behavioral dimensions between the three groups in study population of fibromyalgia syndrome (FMS).

Methods: A nation-wide cross-sectional survey (online and direct interviews) was conducted between 2010-16 to identify first group- 18 (16 male, 2 female) rheumatologists (snowball sampling), and second group- 122 (44 male, 78 female) physical therapists (purposive sampling), both with previous experience of treating adults with fibromyalgia. Also 188 patients with FMS were also studied from outpatient departments of tertiary care hospitals as the third group. All participants filled the Pain Attitudes and Beliefs (PABS) scale and the scores were analysed to identify the two dimensions descriptively in percentiles, and their between-group comparisons were done using Chi-Square test at 95\% confidence interval using SPSS version 22 for Windows software.

Results: There was an overall predominance of biomedical dimension for FMS reported in all three groups, with rheumatologists being most prevalent $(76.8 \%)$, followed by patients $(65.6 \%)$ and then by physical therapists $(54.12) \%$. Betweengroup comparisons were significant $(p<.05)$ for all 6 analyses.

Conclusion: Biomedical dimension was predominantly reported by rhematologists, physical therapists and patients for chronic pain in FMS and this necessitates further research on development and implementation of educational interventions in this part of the world.

References:

[1] Kumar SP, Jim A. Physical therapy in palliative care: from symptom control to quality of life: a critical review. Indian J Palliat Care. 2010;16(3):138-46.

[2] Kumar SP, Jim A, Sisodia V. Effects of Palliative Care Training Program on Knowledge, Attitudes, Beliefs and Experiences Among Student Physiotherapists: A Preliminary Quasi-experimental Study. Indian J Palliat Care. 2011;17(1):47-53.

[3] Kumar SP, Saha S. Mechanism-based Classification of Pain for Physical Therapy Management in Palliative care: A Clinical Commentary. Indian J Palliat Care. 2011;17(1):80-6.

[4] Prem V, Karvannan H, Chakravarthy R, Binukumar B, Jaykumar S, Kumar SP. Attitudes and Beliefs About Chronic Pain Among Nurses-Biomedical or Behavioral? A Cross-sectional Survey. Indian J Palliat Care. 2011;17(3):227-34.

[5] Kumar VK, Kumar SP, Baliga MR. Prevalence of work-related musculoskeletal complaints among dentists in India: a national cross-sectional survey. Indian J Dent Res. 2013;24(4):428-38.

[6] Kumar SP, Kumar A. Evidence-based Practice in Chronic Pain: A Multidimensional Biopsychosocial Paradigm is the "Need of the Hour" in Palliative Care. Indian J Palliat Care. 2013;19(2):126-7

[7] Kumar SP, D'souza M, Sisodia V. Interpersonal communication skills and palliative care: "finding the story behind the story". Indian J Palliat Care. 2014;20(1):62-4.

Acknowledgments: Study participants for their whole-hearted participation and contribution.

Disclosure of Interests: None declared

DOI: 10.1136/annrheumdis-2020-eular.196

\section{THU0649-HPR ASSESSMENT OF THE EFFECTIVENESS OF THE EDUCATIONAL PROGRAM FOR PATIENTS WITH RHEUMATOID ARTHRITIS}

M. Salokhiddinov ${ }^{1}$, F. Umarov ${ }^{1} .{ }^{1}$ Tashkent Medical Academy, Tashkent, Uzbekistan

Background: Effective therapy of rheumatoid arthritis (RA) is impossible without the active and competent participation of the patient in this process, which requires educational programs based on the real needs of the patient

Objectives: The purpose of the study was to develop an educational program for patients with RA and evaluate its effectiveness

Methods: The study included 65 patients with RA. 35 patients of the main group were trained in the educational program. Of these, 30 patients made up the control group. The educational program consisted of 4 daily classes of 90 minutes. Initially and after 6 months, the indices DAS28, HAQ, RAPID3 were determined using the MDHAQ questionnaire
Results: After 6 months after training in the main group, the DAS28 index decreased by $1.28 \pm 0.28$ points $(p<0.05)$, HAQ - by $0.65 \pm 0.39(55.2 \%)$ ( $p$ $<0.01)$, RAPID3 - by $4.87 \pm 0.82(45.6 \%)(p<0.01)$, anxiety level - by $0.78 \pm 0.28$ $(52.1 \%)(p<0.05)$, depression - by $0.76 \pm 0.54(43.4 \%)(p<0.05)$, fatigue - by $2.96 \pm 1.21$ points $(42.3 \%)(p<0,05)$, sleep improved by $0.85 \pm 0.34(52.3 \%)$ ( $p<0.05) .6$ months after participating in the educational program, a good response to treatment according to DAS28 according to EULAR criteria was significantly more often recorded $(54.5 \%$ versus $29.0 \%$ in the control group (p $<0.05$ ), and the number of patients noted improvement well-being increased by 9 times $(p<0.01)$. The dynamics in the control group was less pronounced, which determined statistically significant differences between groups for most indicators $(p<0.05)$

Conclusion: The educational program improves functional capabilities, psychological status, helps control the activity of the disease and improves the quality of life of patients with RA

\section{References:}

[1] Chen SY Wang. The Relationship between Physical Function, Knowledge of Disease, Social Support and Self care behavior in Patients with Rheumatoid Arthritis. Journal of Nursing Research. 2007;15:183-191.

[2] Taal E, Rasker JJ, Seydel ER, Wiegman O. Health Status, adherence with health recommendations, self-efficacy and social support in patients with rheumatoid arthritis. Patient Education \& Counseling. 1993;20:63-76.

Acknowledgments: I would like to thank to all my Prof Ahmedov and department of Rheumatology for their sincere support

Disclosure of Interests: None declared

DOI: 10.1136/annrheumdis-2020-eular.622

\section{THU0650-HPR THE USE OF GAMIFICATION TO MOTIVATE HEALTH PROFESSIONALS IN RHEUMATOLOGY TO PARTICIPATE IN BLENDED LEARNING.}

R. Sengewein ${ }^{1}$, P. Steffens-Korbanka ${ }^{2}$, J. Wendler ${ }^{3}$, M. Kieslich ${ }^{4}$, E. Schmok ${ }^{5}$, G. Gauler6. ${ }^{1}$ Humeo GmbH, Düsseldorf, Germany; ${ }^{2}$ Rheumapraxis an der Hase, Osnabrück, Germany; ${ }^{3}$ Rheumatologische Schwerpunktpraxis, Erlangen, Germany; ${ }^{4}$ Heinrich Heine University Düsseldorf, Düsseldorf, Germany; ${ }^{5}$ University of Lübeck, Lübeck, Germany; ${ }^{2}$ Rheumapraxis an der Hase, Osnabrück, Germany

Background: Blended learning is an increasingly popular learning supplement for traditional classroom-based courses in medical education. Once implemented, many factors influence its success. This was demonstrated by Shivetts et al., who concluded that student motivation plays a major role. In particular, if a learner is not self-motivated, e-learning may not represent the best learning environment. ${ }^{1}$ However, gamification methods are known to enhance motivation in medical education and, if used correctly, can overcome this deficit. ${ }^{2}$ For this purpose, a quiz duel was created and used as a blended learning approach for health professional training in rheumatology. We hypothesize that the use of the quiz duel gamification technique improves learners' motivation to successfully complete their blended learning course.

Objectives: To investigate the potential of gamification methods in motivating health professionals to answer multiple choice questions (MCQs) in a pilot blended learning scenario.

Methods: Four hundred and sixty MCQs were developed in accordance with the learning objectives of a certified training course and integrated into a learn ing management system (LMS). As a gamification technique, a duel mode was created. Course participants had access via an individual user account and used personal smartphones. After each answer was provided, the learners received corrective and explanatory feedback, as well as information on how the duel opponent answered. Incorrectly answered MCQs were repeated in further duels.

Information on the number of MCQs answered (1), days learned (2), and learning time spent (3) was collected and analyzed. Each day on which at least one MCQ was answered counted as a learning day per user. The learning time was calculated with $1.5 \mathrm{~min}$ per $\mathrm{MCQ}$ answered. Analysis was performed over a 15-week period (08/19-12/19).

The training event ("RFAplus") was organized by the Rheumatologische FortbiIdungsakademie $\mathrm{GmbH}$ and took place on three weekends in intervals of fou weeks in Germany. The LMS used was Humeo (Humeo $\mathrm{GmbH}$ ). All users agreed to the terms and conditions of use and data protection before participating in the blended learning intervention.

Results: Nineteen female health professionals in rheumatology participated in the study. The mean age of participants was 43.5 years (range, 21-60 years). The $460 \mathrm{MCQs}$ were answered 20,397 times, with $1039 \mathrm{MCQs}$ per 